\title{
World Heritage and modernity
}

\section{Heritopia}

UNESCO's salvage campaign in Nubia, with the temples of Abu Simbel as its main attraction, was described as a great success both at the time and afterwards. The Aswan High Dam's threats to the ancient monuments could be averted. The temples of Pharaoh Ramses II were saved from the rising water level of the Nile by being cut up, moved, and reassembled in a new and safer place. Heritage had been threatened by Egypt's modernisation, but it was salvaged in an international campaign that employed the rational organisation, finances, knowledge, and technology of modernity in order to succeed.

Even so, despite all the words about success, the campaign appears to have been associated with seven paradoxes, which may be reformulated as questions. The contradictions are to do with the impossibility of preserving the past; the relationship between preservation and change; protection and preservation as an exception; the significance of threats; the relationship between heritage and modernity; trends and tendencies in modernity; and heritage as both local and global. The paradoxes and the associated questions will be discussed in this concluding chapter in order to round up my inquiry, but they will be reviewed in the reverse of the order in which they were first presented.

It was noted that World Heritage, with Abu Simbel as an example, does not at first sight fit in with a postmodern interpretation of the present, since World Heritage is a category for protection and preservation geared to creating structure, unity, wholeness, and universalism. World Heritage as a phenomenon is one of many expressions of a globalisation; but it includes national and local places, where diversity is also deliberately pursued. World Heritage can thus be designated as glocal; that is, a phenomenon that combines the global and the local. But glocality as a concept is not an 
exhaustive answer, since the World Heritage Convention with its list of World Heritage sites crosses borders in several respects: in its intentions; in relation to the categories of nature and culture; in respect of World Heritage themes; and with regard to chronology, geography, and engagement.

The fundamental intention of the World Heritage Convention is to protect and preserve heritage that is viewed as outstanding and universal (WHC 1972: 1). But since the establishment of the Convention, additional objectives to which World Heritage is meant to contribute have also been developed, one example being sustainable development (Operational, 2019: \$6; cf. Bille Larsen $\&$ Logan 2018). However, the overall objective of protection and preservation and the subordinate objective concerning development are not always compatible. Indeed, they may be opposed.

The combination of the categories of nature and culture in the same convention for protection and preservation was presented with pride by the convention's agents (Batisse \& Bolla 2003 (French); 2005 (English)). The great achievement consisted in making two established discourses and bureaucratic fields, each with its own agenda and ambitions, work together. The specific combination of nature and culture is symbolically expressed in the World Heritage emblem - a square inscribed in a circle, designed by the artist Michel Olyff. The emblem is intended to symbolise how "the results of human skills and inspiration" represented by the square are accommodated in and bound up with "gifts of nature" represented by the circle, and how the circle also refers to the globe of the earth (whc.unesco. org; Operational 2019: $\$ \$ \$ 258-279)$. Besides, the emblem may serve to recall the ground plan of a passage grave from the Stone Age, and also, in simplified form, the ground plan of the temples of $\mathrm{Abu}$ Simbel in their artificial hills.

If the division between nature and culture is something characteristic of modernity, we can observe that the Convention of 1972 presented an attempt to unite the two several years before Jean-François Lyotard proclaimed the arrival of the postmodern condition in 1979 (Lyotard 1979 (French); 1984 (English)). But the symbiosis between nature and culture only came about gradually. Until 2004, there were two separate lists of criteria; and even after they were brought together in a single list, it is still obvious that criteria i-vi apply to culture and criteria vii-x to nature. The provision of advice is also split between different bodies with, by and large, ICOMOS for culture and IUCN for nature. The integration is clearer in the 39 so-called "mixed" World Heritage sites 
(WHL, noted in July 2019), examples being the "Holy Mountain" Mount Athos in Greece (WHL 454, 1988) and Machu Picchu in Peru (WHL 274, 1983).

In the same way as the Convention covers both nature and culture, it also accommodates various types of World Heritage that have to be protected and preserved, namely monuments such as buildings and sites, objects that may belong in different institutions and disciplines. The theme of cultural landscapes, which was added in 2002, is a cross-cutting perspective, in which the landscape may contain elements of differing ages (Fowler 2004). There are 112 World Heritage sites that are characterised as cultural landscapes (WHL, noted in July 2019). One example is the Bamiyan Valley in Afghanistan, with the niches of the destroyed Buddha statues as well as other remains (WHL 208rev, 2003).

The chronological range of the Convention is enormous. It extends from nature such as the Grand Canyon in the US, with deposits up to 2 billion years old (WHL 75, 1979), to the Sydney Opera House, which was begun in 1957 and opened in 1973 (WHL 166rev, 2007). Once again, the Convention gathers objects across institutions and disciplines, the Grand Canyon being connected with paleogeology and the Sydney Opera House with modern architectural history.

In conjunction with the World Heritage List, the Convention operates at several geographical levels. It deals with local sites, nominated by the nation for elevation to an international level, where they become not only a national responsibility but also a responsibility for everybody, in practice under the supervision of UNESCO with the World Heritage Centre. More specifically, World Heritage sites may extend across one or more national borders; there are thus 39 "transboundary" World Heritage sites (WHL, July 2019). One example is the Struve Geodetic Arc, a chain of survey triangulations along a meridian through ten countries in Europe from Norway to Ukraine (WHL 1187, 2005); a second example is the Architectural Work of Le Corbusier with buildings in seven countries (WHL 1321rev, 2016); and a third is the Silk Roads through China, Kazakhstan, and Kyrgyzstan (WHL 1442, 2014).

The glocality of World Heritage sites is also reflected by the people involved. Initiatives concerning cultural and natural heritage often begin locally; but they are obliged to persuade a regional and national level, so as to be included in a tentative list and then actually be nominated. Work at local, regional, and national levels may take place in consultation with representatives of the World 
Heritage Centre; and the decision to approve inscription is made by the World Heritage Committee with its 21 representatives, following opinions from ICOMOS, IUCN, and ICCROM as expert bodies. The process up to potential inscription as a World Heritage thus involves a large number of agents with widely different roles, at different levels, and in many countries.

The World Heritage Convention with its World Heritage List crosses borders in a number of areas. Features that would, at first sight, come across as obstacles - such as separate categories, types, periods, or levels - are allowed to work together here. In my view, it is the very cross-border character of the Convention, and of World Heritage, that has laid the foundation for its success. Here international cooperation succeeds - and it cannot be stopped by a veto, as in the UN Security Council. A need is met; and problems have been solved in a relatively pragmatic spirit, in a way that is responsive to current needs and trends.

For despite all the criticism of the World Heritage Convention criticism of the process from initiative to inscription, of the actual selection of World Heritage sites, and of how the World Heritage sites are managed - it is easy to establish that the Convention is a great success. This is seen from accession to the Convention, which proceeded relatively rapidly in the period from 1972 onwards and has since, without defections, reached a level amounting to a global consensus; as of July 2020, even Somalia has ratified the convention. It is also apparent from the tentative lists, in which numerous monuments, buildings, and sites are queuing to become World Heritage sites. Besides, it is clear from the intensive work being done in many places to get a monument, building, site, or landscape on to the tentative list and nominated; some of these efforts are new attempts to win approval after a previous rejection. Places are prepared for nomination, being "modernised" in order to be experienced as relevant.

Two examples of tentative World Heritage sites that I have run into in my work as a historical archaeologist are Viking Monuments and Sites, with cooperation between Denmark, Iceland, Latvia, Norway, and Germany, and The Rise of Systematic Biology, with cooperation between Australia, England, France, the Netherlands, Sweden, and South Africa. The latter example involves botanical gardens and sites from the eighteenth century, places that are linked to the botanist Carl Linnaeus in Sweden (whc.unesco.org). At local, regional, or national levels, there is great keenness to attain World Heritage status for one thing or another. The nomination of a presumptive World Heritage site is associated with great hopes 
for attention, funding, and development. World Heritage status is attractive.

It may briefly and counterfactually be concluded that if the World Heritage Convention had not existed, it would have been necessary to (re)invent it, for the need and its popularity cannot be doubted.

The genius of the Convention is based on its cross-border ambitions and capabilities. It combines the apparently contradictory. The Convention is a creative construction, since it has generated new thinking and practice both about what can be cultural and natural heritage and about what protection and preservation may mean.

World Heritage sites are cross-border and glocal; but the full complexity of the phenomenon is not captured by the glocal concept. A similarity to franchising in business may be pointed out, too; there, payments are made to obtain a share of a well-known brand. In the case of World Heritage, however, the point is not to trade under a certain brand name but to have a right to protection, preservation, and promotion under the World Heritage emblem. States pay UNESCO as well as making both mandatory and voluntary payments to the World Heritage Fund; they may then apply for a monument, a building, a site, or a landscape to be made part of the World Heritage brand, which confers the right to use the Convention's emblem. But most of the responsibility and the work remains local, regional, and national. If the rules are not adhered to, a site may, after warnings, lose the right to call itself a World Heritage site and use the emblem, as happened to the Arabian Oryx Sanctuary in Oman (WHL 654, 1994, delisted 2007) and the Dresden Elbe Valley (WHL 1156, 2004, delisted 2009).

Sites are modernised in order to become World Heritage - and they are modernised after having achieved this status. But in actual fact, nothing happens on inscription. It is a matter of recognition of a pre-existing status. If a site is inscribed in the World Heritage List, it is because it is in fact already outstanding and universal. This is reminiscent of the canonisation of a person as a saint after several stages of scrutiny. The deceased was already a saint, but is now officially deemed to be worthy of the respect due to such a personage. Nonetheless, recognition as a World Heritage after a long and often difficult process is associated with so much hope and prestige. A World Heritage site is not just a material place; it is also a starting point for utopian expectations.

The World Heritage Convention and the inscription of a site as World Heritage adds something invisible. The special status 
or increased value as a World Heritage site is best described as a modern "enchantment" that makes everything possible. The World Heritage site is lifted into its own elevated sphere, a sphere characterised by the immoveable, invaluable, and eternal; here heritage is united with the no-place of utopia, and the sphere may hence be designated as Heritopia.

In Heritopia, paradoxes are no obstacles; if anything, they enhance the enchantment. The analogy with the sacred and religious is thus entirely justified and does not necessarily convey unfavourable connotations. That World Heritage sites by no means remain untouched, but are visited by large numbers of tourists; that they are valued in terms of money, generally in the form of paying visitors and hotel nights; and that they do not remain unchanged, but are actually modernised - all this is part of the narrative of the border-crossing paradoxes inherent in World Heritage.

The new concept Heritopia, made by uniting Heritage and Utopia, signifies the land of the future, which is being pursued with the aid of a modernised heritage and World Heritage. Here, remains of the past are used to create the future in a manner completely opposed to Zygmunt Bauman's depressing concept "Retrotopia". The future is not being sought nostalgically in the past, but looked for as a utopia with the aid of the past. While my inquiry opened with a sense of wonderment about the temples of Abu Simbel and the Nubian campaign, Heritopia may serve to summarise the optimistic final outcome of this inquiry. In more ways than one, Heritopia is a place and a situation to long for.

\section{Regardless of trends}

Both more and less modernity creates heritage. On the one hand, the ambition of modernising Egypt through the Aswan High Dam launched an international campaign in the course of which the cliff temples of Abu Simbel were salvaged and later inscribed in the World Heritage List together with other temples along the Nile. On the other hand, the decline of modernity, the emergence of postmodernity, and deindustrialisation entailed a transition to a "heritage industry". Here income from industrial production is replaced by income from heritage tourism, and at the same time the remains of industry may themselves be reclassified as heritage worth protecting, preserving, and visiting. In Egypt, however, tourism was an important "industry" long before the construction of the Aswan High Dam, indeed before all talk of postmodernism, deindustri- 
alisation, and World Heritage. Ramses II's temples at Abu Simbel have been important destinations ever since their (re)discovery in 1813.

In crisis theories, both more and less modernity can be made to bear the responsibility for varying periods' obsession with the past. Consequently, the more - or less - modernity, the more history, memory, and heritage. The paradox can be explained in several ways, however. First, the view taken of the concept of modernity varies in different crisis interpretations. Second, examples are chosen that may strengthen a particular thesis concerning the past and modernity, while others are overlooked or deliberately excluded. Third, all change can create relics in need of protection and preservation, irrespective of whether a rise or decline of modernity is involved.

An emerging modernity means new ideas, new monuments, buildings, places, and landscapes; but it also means that earlier ideas lose their relevance and that the older infrastructure is transformed, abandoned, or destroyed. Modernity leaves relics that may live on as history, memory, and heritage. But modernity in decline creates relics too. When industry moves to new places or countries with cheaper labour or lower taxes, ideas, technologies, factories, and housing that were modern once become redundant. The creative destruction of ideas as well as materiality is common to both rise and decline.

In view of how heritage may be combined with both modernity and post-modernity, both industrialisation and deindustrialisation, it can be no surprise that the same tendencies appear regarding World Heritage. Here, however, the picture is even clearer. Thus, there are no simple correlations between the establishment of World Heritage and trends in the history of ideas and the economy.

The World Heritage Convention came into being in 1972, right at the end of a unique period of economic growth and confidence in modernity in the West. The Convention was developed in the 1960s during a modern boom, which coincided with the establishing of new states after decolonisation. As an idea, the Convention thus belongs to modernity with its ambition to protect and preserve remains of the past that modernisation is threatening directly, or risks abandoning as useless relics. Shortly after the adoption of the Convention came the turning point of the Oil Crisis of 1973-1974, which marked the end of the economic boom, and of optimism, in the West.

Consequently, the situation had changed when the Convention was to be implemented in practice with the inscription of the 
first World Heritage sites in 1978. The UK, the former colonial great power, was in an economic and political crisis in the 1970s because of deindustrialisation and unemployment. The concept of postmodernism was established to characterise the new tendencies in the history of ideas.

The Convention is managed pragmatically in relation to the new needs of the time, as is seen in varying editions of the Operational Guidelines (most recent from 2019). The Convention was justified by threats and needs for protection and preservation; but its management at the World Heritage Centre came to be about identity, tourism, multiplicity, sustainable development, representativeness, balance, and credibility. More than ever, the Convention is becoming a political project in which choices must be made between different objectives, interests, and values.

One concrete expression of how the Convention is managed as an idea in a period with new conditions and needs is seen in the inscription of industrial heritage as World Heritage. This is a question both of a general interest in the early history of industrialisation with its material remains and of facilities that economic cycles have made redundant. One example of early industrialisation is the Ironbridge Gorge (WHL 371, 1986) in the UK; and an example of a topical closure is the Zollverein Coal Mine Industry in Germany (WHL 975, 2001), where industrial activities ended in 1986.

Another concrete expression of the relevance of the Convention in a new period is the nomination and designation of monuments, buildings, places, and landscapes that have national iconic status. States have proposed and received acceptance for World Heritage sites that are central to the narrative of their country's history and identity, often doing so at a relatively early stage in the Convention's history. Examples include the Giza pyramids in Egypt (WHL 86, 1979), the Persepolis in Iran (WHL 114, 1979), the Taj Mahal in India (WHL 252, 1983), Machu Picchu in Peru (WHL 274, 1983), the Statue of Liberty in New York (WHL 307, 1984), Petra in Jordan (WHL 326, 1985), Great Zimbabwe in Zimbabwe (WHL 364, 1986), the Acropolis in Athens, Greece (WHL 404, 1987), the Great Wall in China (WHL 438, 1987), Uluru (Ayers RockMount Olga) in Australia (WHL 447rev, 1987, 1994), and Jelling in Denmark (WHL 697, 1994, 2018).

A third concrete expression is the modernisation carried out before and/or after sites have been inscribed as World Heritage. This is modernisation both of the sites themselves by providing signs, paths, lighting, and ventilation, and of their surroundings by means 
of the provision of visitor centres, car parks, and access roads - all to make the World Heritage sites attractive as destinations in an expansive tourist industry. One example here is the temples of Abu Simbel (WHL 88, 1979); Stonehenge in England (WHL 373bis, 1986, 2008) is another, and a third is Jelling in Denmark (WHL 697, 1994, 2018).

If the World Heritage Convention and its practical management are seen not only as an antiquarian project for protection and preservation of the outstanding and universal, but also as a political project shaped by states in both rivalry and cooperation, other patterns emerge. First and foremost, note must be taken of the remarkable consensus about the Convention, with ratifications by 193 states (noted in September 2020). The types of World Heritage vary between states, but they appear across economic, political, and religious classifications of the world. Thus, around the same number of World Heritage sites exists in the US $(24 ; 1973$; noted in July 2019), Iran (24; 1975), Russia (29; 1988), and Japan (23; 1992).

Iran ratified the Convention as early as 1975 and obtained its first World Heritage in 1979, the same year as the revolution. But no new World Heritage sites were added in the period 1980-2002. China, which deliberately destroyed remains of the past during the Cultural Revolution in 1966-1976, ratified the Convention in 1985, obtained its first World Heritage in 1987, and now has no fewer than 55 World Heritage sites (WHL, July 2019). We may also note the contrast on the Korean Peninsula, where night-time lights also show a clear difference. Capitalist South Korea ratified the Convention in 1998 and has 14 World Heritage sites, the first being inscribed in 1995. Communist North Korea ratified the Convention in 1998 and only has two World Heritage sites, the first dating from 2004.

The World Heritage Convention is thus interpreted and managed with political pragmatism and remains meaningful regardless of trends. As is the case with World Heritage sites themselves, varying meanings may be ascribed to the Convention so that it remains relevant and therefore "useful".

\section{World Heritage and modernity}

What is the relationship between World Heritage and modernity? This question has been a pivotal point throughout my inquiry. It is the pivotal point for understanding and explaining how the past is apparently seen everywhere, and how history, memory, and 
heritage are expanding. The novel La lenteur (English Slowness) by Milan Kundera formulates an elegant existential mathematics: "le degré de la lenteur est directement proportionnel à l'intensité de la mémoire; le degré de la vitesse est directement proportionnel à l'intensité de l'oubli" (Kundera 1995 (French): 45; 1995 (English): 39 , "the degree of slowness is directly proportional to the intensity of memory; the degree of speed is directly proportional to the intensity of forgetting”).

Similarly, the relationship between modernity and heritage has often been expressed in a formula, but the concepts that are used in it may vary. For modernity and World Heritage are examples of concepts from a broad field of dichotomies, in which expressions of the future and of the past are set up as opposites. Concepts that may be entered on one side of the dividing line are change, progress, modernity, modernisation, modernism, industrialisation, urbanisation, and secularisation, and concepts that may be written on the other side are history, memory, heritage, tradition, monuments, memorials, museums, conservation, and nostalgia. When modernity increases, so should nostalgia. But paradoxically, when modernity decreases, nostalgia also increases. The formulas synthesise statements or chains of arguments that are seldom if ever accompanied by concrete qualitative reasoning or by the adducing of quantitative evidence.

The point of an "existential mathematics" is undoubtedly to bring persuasive precision and clarity to bear on a problem area in the humanities. At first sight, the formulas look plausible; but the paradoxes that gradually become visible reveal that the assumptions regarding the mathematics are dubious. The paradoxes arise because the concepts that are used are complex, ambiguous, and entangled with one another.

Modernity thus has several faces. It is associated with speed, volatility, and renewal, both in the world of ideas and in the material world. Modernity is therefore connected with the universal ideas of the Enlightenment and with the market economy and its creative destruction.

World Heritage has several faces too. As part of heritage, World Heritage can be associated with the unchanging, with stasis and the past; but the examples of World Heritage include modern ones representing change, speed, and the future. On the one hand, World Heritage as such is a modern concept, linked to the international system organised around the UN that evolved after the Second World War. The World Heritage Convention is managed by 
a Centre, where the process from tentative lists via nomination to inscription and monitoring is rationally regulated down to the very last bureaucratic detail. On the other hand, World Heritage sites are concrete material monuments, buildings, places, and landscapes that may belong to widely different periods, including the modern era.

We perceive the complex, ambiguous, and entangled not only in the ideal world of concepts, but also in encounters with concrete World Heritage sites. Ramses II's cliff temples at Abu Simbel with their sculptures and images have more or less survived for thousands of years. Consequently, the ancient temples may stand out as a contrast to the modern Aswan High Dam with its turbines and production of electricity. The dam threatened the very existence of the temples, but they survived thanks to a modern international salvage campaign. The temples were sawn into pieces, moved, and recreated in a concrete structure, which an attempt has been made to conceal. The cliff temples thus mix the old and the new. Abu Simbel also acts as one of several important destinations in the Egyptian tourist industry, a place that tourists visit for a few hours.

To deepen the confusion, the canonical tradition of heritage considers that modernity often threatens heritage and World Heritage. But at Abu Simbel, modernity was both a threat (the dam) and a solution to the problem (the salvage campaign). The temples were salvaged by engineers and archaeologists using the most modern knowledge and technology of their time, which may itself become a recognised part of World Heritage in the future: an outstanding and universal "monument to the engineering skill" of the $1960 \mathrm{~s}$ (cf. Berg 1978: 49). In the critical tradition of heritage, both modernity and heritage may, by contrast, constitute a threat. What is a threat and what is threatened is hence a relative matter.

In my humanities-based mathematics I would instead, despite the conceptual complications, like to call attention to the emergence of a compensatory chain reaction: hypermodernity or the Anthropocene, where humans radically influence nature and society and there is an initial compensatory counter-reaction, with more and more being held up as being natural and cultural heritage worth protecting and preserving for several reasons. As a second compensatory reaction against this inflation of natural and cultural heritage, World Heritage is then constructed as a clearly defined and separate category of its own. And whereas the increase in the changes of modernity and the compensatory expansion in 
natural and cultural heritage are exponential, the increase in World Heritage is, in principle, linear, with an extremely limited number of new sites each year.

\section{Threats, realities, and rhetoric}

Threats of change, decay, or destruction are central to the first, and canonical, culture of heritage. For threats of destruction or change are crucial in establishing remains of the past as heritage. Actual or imagined threats may activate an opinion and generate action and legislation. The mission of the canonical culture is to avert threats to heritage, to protect and preserve it.

Threats of change, decay, or destruction are also central to the second, and critical, culture of heritage. Here, that which is threatened is itself transformed into a threat. For heritage can be an actual or imagined obstacle to development. Criticism of heritage is sometimes transmuted into a particular fascination with change, decay, and destruction. And since heritage is regarded as a constructed category, and therefore as an infinite resource, not only may sustainable use be acceptable but consumption may be so as well.

Threats thus create heritage, and heritage creates threats. Modernity may be one such threat to parts of heritage, at the same time as aspects of modernity may themselves become heritage. So the relationship between threat, heritage, and modernity is, at first sight, confusing and riddled with contradictions. But the paradoxes are due to the simple fact that what is being threatened and what is doing the threatening depends entirely on the perspective applied.

The importance of a threat in activating opinion, generating action, and transforming monuments into World Heritage is graphically illustrated at Abu Simbel (WHL 88, 1979). The construction of the Aswan High Dam threatened the cliff temples with flooding and thereby with destruction. The threat was obvious and could be followed almost day by day in the steadily rising level of the Nile. The patent contrast between present and past, between modernisation and the monuments, between the dam and the cliff temples, created the drama, narrative, and focus necessary for enabling UNESCO to justify, set up, and implement an international salvage action.

The threats to the monuments in Nubia form part of the background to the establishment of the World Heritage Convention. But the background contains other instances of destruction as well, caused by both people and nature. This is the experience of 
the massive devastation of heritage during the First and Second World Wars. And alongside Abu Simbel, emphasis was placed on UNESCO's action after a natural disaster when wind, high water levels, and violent rain caused flooding in Venice and Florence, Trento and Siena in 1966; subsequently, Venice and its lagoons (WHL 394, 1987), Florence (WHL 174bis, 1982, 2015), and Siena (WHL 717, 1995) all became World Heritage sites.

The World Heritage Convention begins by mentioning the need to protect the outstanding and universal; protection presupposes that something is a threat. And here the Convention explicitly asserts that the heritage is "increasingly threatened". Later, the Convention goes on to specify different threats in detail (WHC 1972: 1 quotation, Article 11: 4).

The importance of threats in the management of the Convention is also shown by the special list of World Heritage in Danger. Here, it is a formal decision that determines - after an investigation, and according to set criteria - whether a World Heritage site should be entered on the list of World Heritage in Danger. The decision is made at the annual meeting of the World Heritage Committee

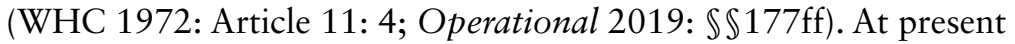
(2019), there are 53 World Heritage sites on the list: 36 cultural and 17 natural in a total of 33 countries, including Jerusalem (whc. unesco.org/en/158; July 2019).

But whether a World Heritage site is threatened or itself constitutes a threat depends on the choice of perspective. At the Dresden Elbe Valley, the plans to build a new motorway bridge of steel and concrete meant that the area was first placed on the list of World Heritage in Danger in 2006 and was then deprived of its status as a World Heritage site in 2009. The matter was presented in an obviously menacing tone by UNESCO: if the bridge was put in place, Dresden would be removed from the World Heritage List. And to make matters clear, Dresden is still on the list, but it has been crossed out (WHL 1156, 2004, delisted 2009)! Here, World Heritage and modernity are presented as each other's opposites. But they could also have been integrated, if the modern bridge had been accepted as part of the World Heritage site. And viewed from another perspective, it was UNESCO's management of the World Heritage site that became a threat to a solution of present-day traffic problems.

Considering that the Dresden Elbe Valley has bridges from different periods, it is strange that the most recent bridge was not interpreted as part of the World Heritage site, as a new annual ring in a historical development. First, modernity is not necessarily an obstacle to status 
as World Heritage; there are many modern World Heritage sites, including some that are built in concrete. Second, there are World Heritage sites where modern restoration and reconstruction have contributed to the sites becoming World Heritage. Examples are Warsaw city centre, which was reconstructed in the period 1945-1984 (WHL 30bis, 1980, 2014), and Carcassonne (WHL 345rev, 1997) in France, which was restored in 1853-1879. In the same way, the definition of the World Heritage Nubian Monuments from Abu Simbel to Philae (WHL 88, 1979) could be expanded to include the international salvage campaign, with its modern relocation and reconstruction of the Abu Simbel temples beneath arched domes made of concrete.

It is relatively easy to demonstrate inconsistencies in relation to changes in monuments, buildings, places, and landscapes. Old modernities are acceptable, but new ones are not. Graffiti on the leg of Ramses II in front of the great temple, containing the Greek name Potasimto - the military commander of an expedition to Nubia in 592 все - is part of World Heritage, as is the name Belzoni from 1817 inside the temple along with other older inscriptions (MacQuitty 1965: 76, 84, 91, 98f, 134; Desroches-Noblecourt \& Gerster 1968: 30f; Grove \& Thomas 2014: front cover). But when a local teenager sprayed "GELWANE" on the great rune-stone of the Jelling monument in 2011, the green paint was carefully removed, and not many months passed before the rune-stones were protected in outdoor display cases (Hvass 2011: 14ff, 66ff). In Abu Simbel, the graffiti is history to admire - in Jelling, it is heritage crime, which triggered a court order for psychiatric treatment and the payment of compensation for cleaning the stone. The context determines the choice.

At Abu Simbel, the volume of tourists has been regarded as a problem. To reduce damage, Nile cruises were not to be allowed to moor directly at the temples (Hassan 2007: 91). But that was before the Arab Spring.

Venice came into focus again in the summer of 2017. Now, however, the issue was not rising water-levels threatening destruction but tourists. One reason is the rise in tourism, to which listing as a World Heritage site has contributed, although tourism to Venice has a long history. There were even demonstrations against mass tourism and its consequences. Other tourist destinations such as Oxford, Barcelona, San Sebastian, and Palma in Majorca also saw protests, demonstrations, and actions that same summer.

That the defence of a World Heritage site may threaten a modern development became apparent in Dresden, just as it obviously 
threatens everyday life in Venice; but can the World Heritage Convention itself come under threat as an international convention despite the present consensus? Yes: if "Pax Americana", the global world order after the Second World War with organisations such as the UN and UNESCO, falls, the convention will fall as well. Michel Batisse wrote, "[l]ike many international agreements, the World Heritage Convention remains a fragile instrument, and the list could be seen as a sophisticated house of cards that could tumble down in a storm" (Batisse 1992: 32). In this context, it may be noted that on 31 December 2018, both the US and Israel withdrew from UNESCO. The inscription of Hebron/Al-Khalil Old Town on the West Bank as a World Heritage site (WHL 1565, 2017), and as World Heritage in Danger (whc.unesco.org/en/158) at the same time, is said to have been a contributing factor.

Threats are rhetorical expressions denoting an undesirable change. When a change is desirable, it is described as progress; when it is considered undesirable, it is described as a backward step and, at worst, as a threat. If the aim is to establish sites as heritage and World Heritage, they are represented as threatened and in need of protection; and to critical observers, the sites themselves may constitute a threat. And in the same way, modernity may be both threatening and threatened.

\section{Conspicuous protection}

Nubian Monuments from Abu Simbel to Philae were salvaged in UNESCO's international campaign and then inscribed in the World Heritage List (WHL 88, 1979). The outstanding and universal was salvaged. Monuments, buildings, and places that were not as spectacular disappeared into Lake Nasser, after having been examined and documented. Other remains could never be examined, however, and had to be denied priority.

World Heritage, the outstanding and universal, is protected and preserved for future generations; but what happens to everything else? That the outstanding must be an exception cannot come as a surprise. But is World Heritage merely an alibi, so that the outside world can be changed, modernised, or destroyed more or less freely? A temporal reservation for relics of the past? And, more generally, are history, memory, and heritage only islands in a sea dominated by silence, oblivion, and vandalism?

That a World Heritage site may indeed be an exception is seen from the example of Auschwitz-Birkenau (WHL 31, 1979). The 
Nazi death camp is a profoundly unsettling metonymic icon of the Holocaust; it is concrete, material testimony to something much more extensive that can be difficult to comprehend. Despite the size of the camp, it was only the centre of a complex with shorter and longer-term satellites, the great majority of which disappeared long ago. Moreover, Auschwitz-Birkenau was one of several death camps, and there were concentration camps and sites where people also died or were murdered across most of Europe (Snyder 2015: 207ff). These matters are not consigned to silence, oblivion, and destruction, although Auschwitz-Birkenau has been given most attention and also World Heritage status. Even so, there are repeated attempts to ignore, minimise, or deny the Holocaust; and here the protection and preservation of actual sites may be of importance as concrete testimony.

The Bridge in Mostar in Bosnia-Herzegovina (WHL 946rev, 2005), the Buddha statues in Bamiyan Valley in Afghanistan (WHL 208rev, 2003), and Palmyra in Syria (WHL 23bis, 1980, 2017) are iconic World Heritage sites that have been vandalised. The sites and their destruction have come in for a great deal of attention; but they are only the tip of an iceberg. Many more and other material and intangible remains of the past, and also of the present, have been vandalised or plundered in wars in these countries without receiving the same attention.

When the Hanseatic Town of Visby on the island of Gotland in Sweden (WHL 731, 1995) became a World Heritage site, this did not mean that change and destruction could be given free rein outside the town wall. In modern, well-organised Sweden, there are rules for development and changes that cover all environments. Consequently, Visby as a World Heritage site is no alibi for changing Gotland's rural districts, even though the degree of protection and preservation may vary from place to place.

When more and more is changed and when, as a psychological reaction, more and more is regarded as heritage worth protecting and preserving, then World Heritage constitutes a special prioritisation of the outstanding and universal. As a reaction against the inflation in the concept of heritage, which has become boundless, a category of conspicuous World Heritage is established with clear distinguishing criteria that have to be met for inscription to be granted. World Heritage becomes something conspicuous, exclusive, and "enchanting" in the mass of gradually "disenchanting" heritage.

The heritage inflation affects both traditions of heritage. When everything can be heritage, the canonical tradition chooses to take 
the initiative for a new currency with a higher value, namely World Heritage. For something to be designated as an outstanding and universal World Heritage site, set criteria have to be met, and the path goes through a long and strictly regulated process. By contrast, the critical tradition is indignant about the omnipresence of the past and at the increase in heritage, which is held to be threatening. It prefers either "real" history or, at the very least, a different selection of heritage.

But both heritage traditions fail to see that the whole field of history, memory, and heritage is growing because change in society in general is accelerating. And while the focus is on protection and preservation as something either positive or negative, all the more is changed or disappears. While the number of World Heritage sites rises each year under strictly regulated forms, all the more monuments, buildings, places, and landscapes change or disappear. If something needs to be discussed or managed, it is thus not heritage or World Heritage but the underlying causes - the global acceleration of change in both nature and culture.

\section{Permanence through change}

The endeavours to protect and preserve heritage lead to heritage changing. However, what is central about heritage is neither preservation, as held by most members of the canonical tradition of heritage, nor change, as is argued by some members of the critical tradition of heritage, but the relationship between preservation and change. Similarly, authenticity - the central capital of heritage - is affected by efforts to protect and preserve.

The preservation of the cliff temples at Abu Simbel took place at the expense of extensive change to the temples themselves and their surroundings. The temples had to be sawn into pieces, lifted away, and reconstructed under concrete arched domes in a new and safe site, using modern technology and materials. The nearby landscape was also changed radically. The cliffs into which the temples were originally carved were replaced by artificial hills. Ramses II had been reflected in the Nile for thousands of years, but now a large lake is spread out in front of the temples. And a new settlement grew up alongside the destinations.

More examples of protection and preservation initiatives leading to changes may be adduced. The Lascaux Cave in France (WHL 85,1979 ) had to close as early as 1963 because the many visitors altered the climate inside the cave, affecting the Palaeolithic images; 
thereafter, access was relatively restrictive. But since 1983, tourists are able to visit a modern replica of the World Heritage site instead. At Stonehenge in England, visitors are not allowed to approach the monument itself either, except on certain occasions. And here the surrounding landscape was altered for the sake of tourism, with the construction or removal of paths, roads, parking places, and a visitor centre (WHL 373bis, 1986, 2008).

The establishment of the Jelling monuments in Denmark (WHL 697, 1994, 2018) as heritage and World Heritage has taken place at the expense of great changes both to the monuments themselves and to their surroundings. Many surrounding buildings were demolished to clear the site, traffic was reorganised, the church was restored several times, the rune-stones were placed in display cases made of glass, a new visitor centre was constructed, and the archaeological finds of a stone ship, a palisade, and halls were marked clearly in the terrain. The modern alterations to the Jelling monuments may, with time, become part of the narrative about the history of the site and therefore part of the World Heritage. The GELWANE inscription might also have formed part of the World Heritage, as has happened with graffiti at other sites.

The protection and preservation of tentative, nominated, or actual World Heritage sites may be dependent on, or lead to, antiquarian or environmental interventions such as conservation, restoration, reconstruction, and nature conservation. Archaeological investigations can also be carried out so as to obtain more knowledge about a monument, a building, a place, or a landscape.

That protection and preservation for the future is best achieved through continued use, not through functioning as a "museum", has long been a widely held antiquarian attitude. The use involved is often aimed at tourism; but buildings can also be arranged so that they can continue to serve practical purposes, in fortunate cases supporting themselves financially, for instance as housing or as exhibition spaces, assembly rooms, or conference premises. Tourism and continued use may then require alterations to the property itself and to its surroundings with signage, lighting, ventilation, disability adaptation, lifts, sprinkler systems, emergency exits, toilets, a restaurant, and the construction of paths, roads, a car park, and a visitor centre.

World Heritage is modernised in order to remain relevant in the present. The purpose of this modernisation is that by being renewed or made topical, the World Heritage site will remain useful in the face of current requirements - and will therefore also 
stand a realistic chance to live on for the benefit of future generations. Present-day needs may be to do with knowledge, on-site experiencing, or ethics. They may involve national identity or experience tourism. The modernisation of a World Heritage site brings it into the present. The same process also applies to large parts of heritage in general, which are being adapted to the role of tourist destination.

The changes are bound to lead to a debate in which different values, views, and objectives may collide since they are not immediately compatible, as Alois Riegl observed many years ago (Riegl 1903 (German); 1929 (German); 1982 (English)). The canonical tradition of heritage might be particularly critical of interventions that affect authenticity. But the canonical and the critical tradition will often be able to agree to reject a modernisation that serves commercial objectives, and to view mass tourism as a threat; profit and popularity are controversial across the heritage divide.

When it comes to the concept of authenticity, things are not that simple. The original feature may relate to the material, to the work process, or to the context. Here I would like to see greater freedom in the use of "creative anachronism", in which old and new are combined in new ways (e.g. Petersson 2017). One example is spolia, where ancient building components were reused in medieval contexts and given new meanings there. Another example in which new and old, fact and fiction, are combined is the film Marie Antoinette by the author and director Sofia Coppola. This film shows the story of the French Queen at Versailles. The narrative and the environment are more or less historically correct; but the colours are exaggerated and the attitudes and music modern, all in order to create proximity and understanding in the present (Coppola 2006 film).

For its time, UNESCO's international salvage campaign was ambitious and bold. But Abu Simbel represents a more discreet example of creative anachronism. Old and new were combined to protect, preserve, and reuse for the future. Both the monuments themselves and their surroundings were renewed, but apart from artificial lighting and ventilation, the modern interventions were concealed from visitors. The cliff temples are intended to appear to be authentic in the material sense - as if nothing had happened since the time of Ramses II.

Here it is tempting to quote from the novel Il Gattopardo (English The Leopard) by Giuseppe Tomasi di Lampedusa: "Se vogliamo che tutto rimanga come è, bisogna che tutto cambi" (Lampedusa 1958 (Italian): 42; 2007 (English): 19; "If we want things to stay 
as they are, things will have to change"). But the quotation does not describe what has happened at Abu Simbel and other World Heritage sites. Things do not stay just as they have been, and everything does not need to change. Some things are modernised; others are not. Permanence for the future is created through change, in which the two dimensions of the concept of time balance each other: greater permanence in some parts may mean more change in others.

\section{Sisyphus and Abu Simbel's stone}

Is it possible and meaningful to try to protect and preserve $\mathrm{Abu}$ Simbel's temples and other World Heritage sites for the future? Is this not impossible and therefore meaningless? For no preservation campaign or move, no elevation to heritage or World Heritage, can prevent change, degradation, and impermanence in the long run.

In the first and canonical heritage tradition, heritage is frequently described as a resource; in the second and critical tradition, heritage is described as a liability. Even an Annales historian may characterise the past as something that needs to be handled so as not to be a burden. Lucien Febvre thus writes about "L'Histoire, qui est un moyen d'organiser le passé pour l'empêcher de trop peser sur les épaules des hommes" (Febvre 1949 (French): 245; 1973 (English): 41; "History is a way of organising the past so that it does not weigh too heavily on the shoulders of men"). Inspired by this, I would argue that World Heritage is a way of setting priorities among natural and cultural heritage phenomena, so that they do not weigh too heavily on human shoulders. But is World Heritage also a burden to be borne into the future?

This brings Sisyphus, King of Corinth, to mind once more Sisyphus who pushes a great stone up a mountain, from whose top the stone rolls down to the plain again. Sisyphus toils uselessly forever in the land of the dead as punishment for having put Death in chains; that is, for trying to prevent impermanence. The philosopher and author Albert Camus used this myth in order to discuss the hopeless situation of human beings (Camus 1942 (French): 163ff; 2005 (English): 107ff). A few years later, however, Camus changed his standpoint and called for an idealist revolt against the absurdity of life, a revolt against merely accepting one's fate, a revolt against "amor fati" (Camus 1951 (French); 1991 (English)).

Sisyphus is a mythical person who does not need to have existed. Myths are not expected to reflect an ancient reality, but they can communicate existential experiences. The story of Sisyphus is 
known from ancient images and from Homer's epics The Iliad and The Odyssey (Homer, The Iliad: VI 153f; The Odyssey: XI 593), epics dated to the eighth century $\mathrm{BCE}$, although the existence of Homer is open to discussion. Sisyphus has since been commented on and illustrated countless times. Camus thus reuses parts of a both material and intangible heritage in order to reflect on topical (and eternal) issues.

Above the ancient city of Corinth on the plains of Greece, there rises a steep hill bearing the ruins of Acrocorinth, which may have inspired the myth's tale of the great stone rolling down the hillside. I would like to interpret Sisyphus's stone not as a boulder that happened to be lying around but as an ancient worked stone that can be reused time and again. Both Sisyphus and his stone are spolia from the past.

The stones of Abu Simbel were not rolled; they were raised up and laid down in a new place. They ought to sit there securely for many generations to come. One of Ramses II's heads fell off during his reign, and it has been left lying on the ground after the reconstruction. But Abu Simbel is no longer two pharaonic temples; that was long ago. They have been transmuted into destinations in Egypt's international tourist industry. The stones of the temple have therefore been given a new meaning.

So, yes, it is possible to protect and preserve Abu Simbel's temples and other World Heritage sites for the future. With modernity, the technological possibilities of protecting and preserving remains of the past have increased dramatically, providing that a more open interpretation of the concepts of preservation and authenticity is accepted. As at Abu Simbel, preservation may involve change, a relocation, and modernisation. And authenticity does not necessarily have to be defined in terms of the material remaining intact.

Preserving remains of the past by transforming them into documentation is no novel idea. This is done every day in archaeological investigations. What is relatively new is that digitalisation using 3D technology makes detailed documentation and reconstruction possible. DNA technology might be of use in recreating threatened or extinct animal species. In addition, in a more traditional and practical vein, monuments, buildings, places - and why not also landscapes - can be moved to new locations where they are no longer threatened, as happened at Abu Simbel.

And, yes, it is also meaningful to protect and preserve Abu Simbel's temples and other World Heritages for the future. For like spolia, the monuments, buildings, places, and landscapes of the 
past can be reused in new and unforeseen contexts. Consequently, protecting and preserving the past for the future is no Sisyphean labour - doing so is both feasible and meaningful.

Remains of the past, such as the temples of Abu Simbel and the myth of Sisyphus of Corinth, are not only good to think with or to visit, but also good as a starting point for action. In the encounter with the past, it is possible to formulate new knowledge, narratives, and ethical reflections that may be put to use in facing the challenges of the present and the future. And there are enough challenges to address. 